\title{
Statistical Properties of Aftershocks for Ahar-Varzeghan Twin Earthquakes on 11 August 2012, NW Iran, and Investigation of Seismicity of North Tabriz Fault
}

\author{
Jamileh Vasheghani Farahani \\ Institute of Geophysics, University of Tehran, Tehran, Iran \\ Email: J_farahani@ut.ac.ir
}

How to cite this paper: Farahani, J.V. (2018) Statistical Properties of Aftershocks for Ahar-Varzeghan Twin Earthquakes on 11 August 2012, NW Iran, and Investigation of Seismicity of North Tabriz Fault. International Journal of Geosciences, 9, 106-118.

https://doi.org/10.4236/ijg.2018.92007

Received: December 5, 2017

Accepted: February 23, 2018

Published: February 26, 2018

Copyright $\odot 2018$ by author and Scientific Research Publishing Inc. This work is licensed under the Creative Commons Attribution International License (CC BY 4.0).

http://creativecommons.org/licenses/by/4.0/

\section{Open Access}

\begin{abstract}
Two earthquakes occurred on 11 August 2012 in East Azerbaijan province, NW Iran with Mw 6.3 at 12:23:15.9 and Mw 6.1; 11 minutes after the first shock at 12:34:34.8 GMT time. In this study, we concentrated on the properties of the aftershock sequences in a duration of 7.5-month time-period data after the main shocks, recorded by Broadband Iranian Network (BIN). We obtained $\mathrm{p}, \mathrm{c}$ and $\mathrm{K}$ parameters with the maximum likelihood method and the occurrence rate was modeled by the modified Omori formula. Besides, we showed that aftershocks of the aftershock in 7 Nov. $2012(M=5.6)$ also decay according to the modified Omori law. We investigated the spatial and temporal variations of $\mathrm{b}$-values before and after the twin earthquakes with Mw 6.3 and Mw 6.1 approximately $20 \mathrm{~km}$ around North Tabriz Fault (NTF) in the region from 1996 to 2013 using Iranian Seismological Center (IRSC). We believed that a research of the past 17 years has clearly established that spatial b-value changes and seismicity rate are highly significant and meaningful. Moreover, our research led to a warning for a probable strong motion along NTF for the coming couple of years.
\end{abstract}

\section{Keywords}

Ahar-Varzeghan Twin Earthquakes, Aftershocks, B-Value, Modified Omori Law, Azerbaijan Province

\section{Introduction}

Situated in the north west of Iran, Tabriz has been severely damaged by several historical strong events in the past. One of the most important faults that caused 
many historical strong motions in Tabriz region is North Tabriz Fault. On 11 August 2012, Ahar region in the East Azarbaijan province experienced two strong earthquakes with Mw 6.3 and 6.1 [1]. Seismic events often have aftershocks that may cause a second hazard for buildings. Beside this fact, aftershocks data have useful information about stress changes and source properties of the mainshocks by checking several parameters such as b-value estimations, decay rate of aftershocks with time, and seismicity rate. There are some relations that express aftershocks activity such as the Gutenberg-Richter's and the modified Omori's laws. These laws describe the size distribution of earthquakes and the decay rate of the aftershock activity, respectively [2]. Gutenberg-Richter relation [3] or frequency-magnitude empirical equation is: $\log (N)=a-b M$, where $N$ is the cumulative number of earthquakes with the magnitude bigger than $M$, a and $\mathrm{b}$ are constants. B-value usually varies between 0.6 and 1.0. It is $>1$ for regions with abundant earthquake swarms. These regions probably have a weak crust that cannot support high strain and heterogeneous stress [4] [5]. Moreover, aftershock sequences are described by the modified Omori law [6]. Our catalog recorded by Broadband Iranian Network (BIN) contained 494 aftershocks with $M \geq 2.5$ in the zone. In the present study, we assessed statistical properties of aftershock sequences and investigated seismicity of North Tabriz Fault.

\section{Tectonic Background and North Tabriz Fault Seismicity}

Tabriz is located in the northwest of Iran. Located among west of Caspian Sea, south of Caucasus thrust belt, east of Anatolia and north of Zagros mountain range. The North Tabriz Fault is the most important structure in northwest of Iran with NW-SE trend. Hessami et al., [7] believed that geomorphic features and paleoseismological studies northwest of Tabriz are a confirmation for repeated surface faulting events in North Tabriz Fault (NTF). North Tabriz Fault can be followed approximately continuously at the foot of the northern mountains near Tabriz for about $100 \mathrm{~km}$, from Mishu Mountain in the west to Bostanabad in the east [8]. Moreover, in 1997, NTF was divided by Berberian into some segments that determined by a series of surface ruptures from the earthquakes of 1721, 1780 and 1786 AD. He believed that NTF has a total length of approximately $210 \mathrm{~km}$ and is a complex northwest-trending structure. Besides, NTF includes proof of right lateral strike slip and vertical displacement with the north side up [9]. There are several historical strong motions in the earthquake records of Tabriz the first of which occurred in 634 A.D. The most destructive events occurred in 634, 1441, 1522 and 1780 [8]. Figure 1 shows the epicenters for some of the most important historical earthquakes in Tabriz region.

There is an important issue about Tabriz region that NTF has a long seismic gap for a strong motion. According to data from Statistical center of Iran in 2011 , the population for the city and the outskirts of Tabriz is about 2,404,697 people. Therefore, seismic studies for the city and its surroundings are matters of great importance. Seismicity in Tabriz region is shown in Figure 2. 


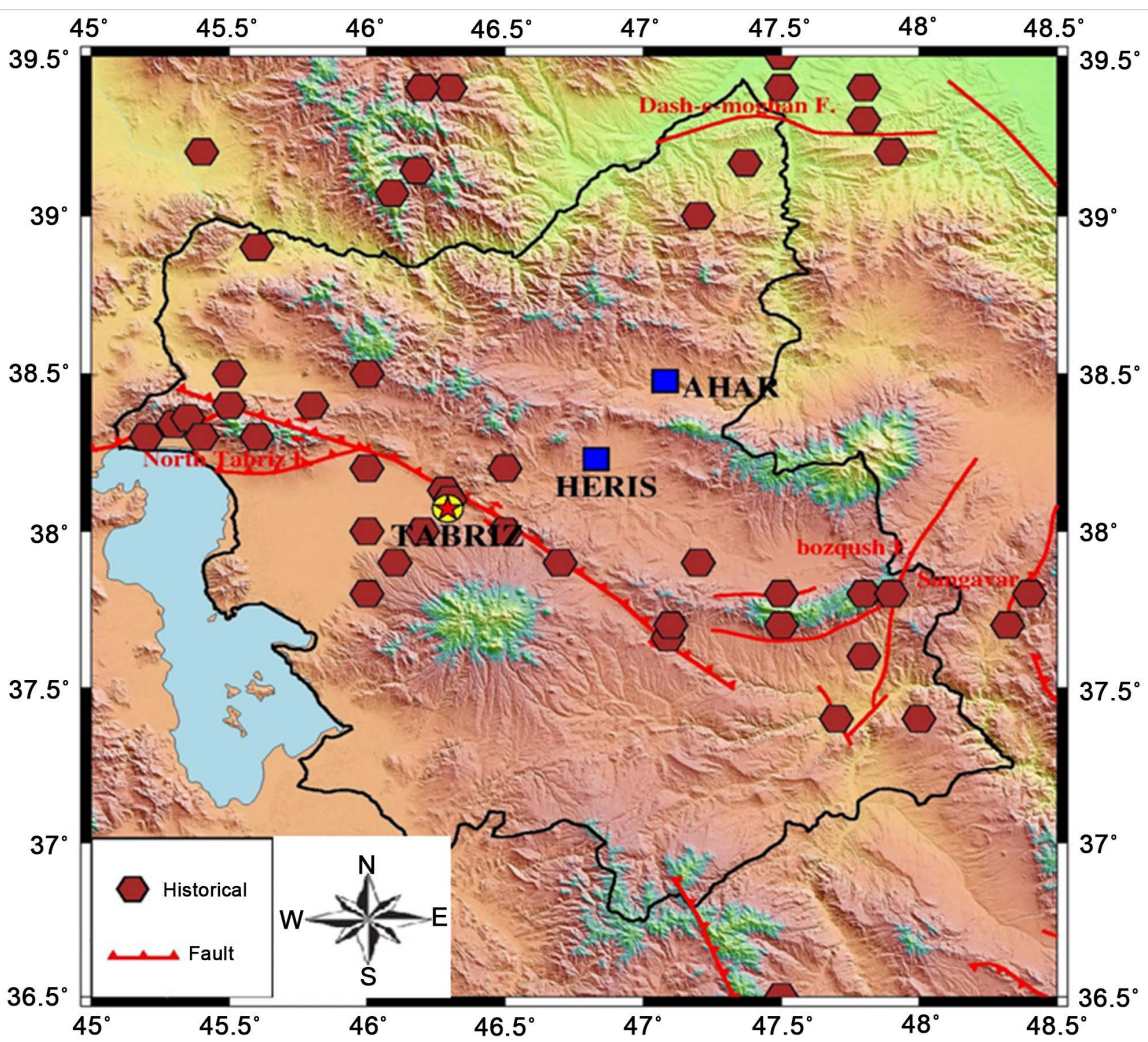

Figure 1. Historical seismicity of north-central Iran.

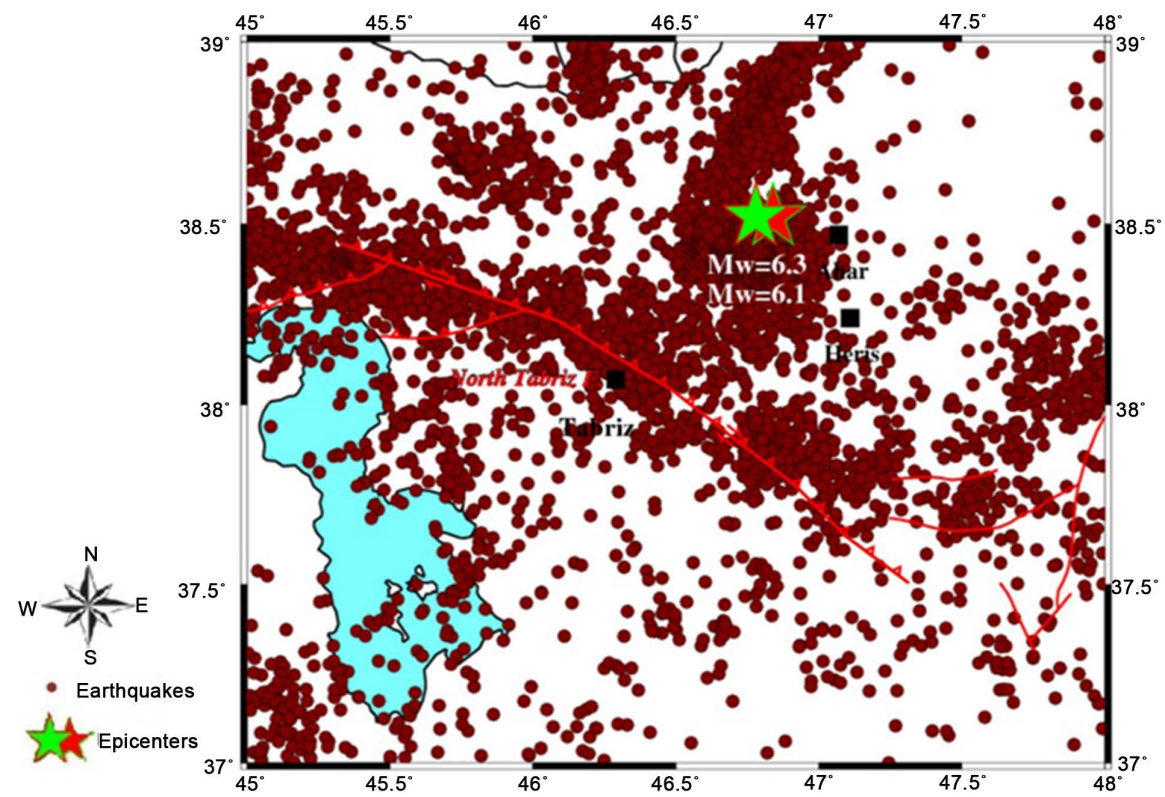

Figure 2. Instrumental seismicity of East Azerbaijan province.

\section{Statistical Properties of Aftershocks}

In any major seismic activity, aftershocks are an important part for researches. They occur due to static and dynamic stress redistribution in nearby main shocks [10] [11]. One of the most important topics in seismology is the statistical 
properties of aftershocks occurrence. In this study, the Ahar-Varzeghan aftershocks are considered in order to analyze their spatial and temporal variations. First, we try to plot only aftershocks in an independent map. Figure 3 shows the hypocenters of the aftershock sequences of the two earthquakes. The strongest trend of events (all sizes of shocks in general with $M \geq 2.5$ ) is observed East-West part along the surface rupture of Varzeghan earthquake on 11 August 2012, in which the highest density of events concentrated in west of Ahar (the north of Heris). The aftershock sequences of the two earthquakes contain about 7.5-month time period, that is from the time of the mainshock (11 August 2012) until 30 March 2013, about 494 data for the twin earthquakes. We had three large events for aftershocks $(M>5.0)$, especially occurred after 3 and 4 days ( $M$ $=5.2$ and 5.1 , respectively $)$ and 3 months $(M=5.6)$ from the time of the mainshocks.

Besides, assessing the magnitude of completeness for earthquake catalogs is an essential step for any seismicity analysis. The magnitude of completeness (Mc) is defined as the lowest magnitude at which $100 \%$ of the events in a space-time volume are detected [12] and [13]. Moreover, Wiemer and Katsumata, [14] believed that the completeness in magnitude varies as a function of space and time. In this study, the magnitude of completeness $(\mathrm{Mc})$ is determined for aftershocks. $\mathrm{Mc}$ is estimated for samples of 20 events/window for the 11 August 2012 earthquakes. The variations of Mc with time for aftershocks are shown in Figure 4. At the first day of the earthquakes (11 August 2012), the highest of aftershocks occurred with $\mathrm{Mc}, 4.0$ for $\mathrm{M} \geq 2.5$ in our catalog and then decreased to about 3.0 and 2.9. Finally, after about two days from the mainshock, it changed to 2.5 . It also changed to about 2.8 after about 80 days and then again decreased to 2.5. Besides, we showed that the temporal distribution of aftershocks is empirically well-described by the modified Omori law [6] through the following equation:

$$
n(t)=K /(t+c) p
$$

where $n(t)$ is the frequency of aftershocks per unit time at time $t$ after the main shock, and $k, c$, and $\mathrm{p}$ are constants. C-value is a constant time that relates to the rate of aftershocks in the early part of an aftershock sequence, $K$ depends on the total number of events in the catalog of aftershocks, and $c$ depends on the rate of activity in the earliest part of the aftershocks.

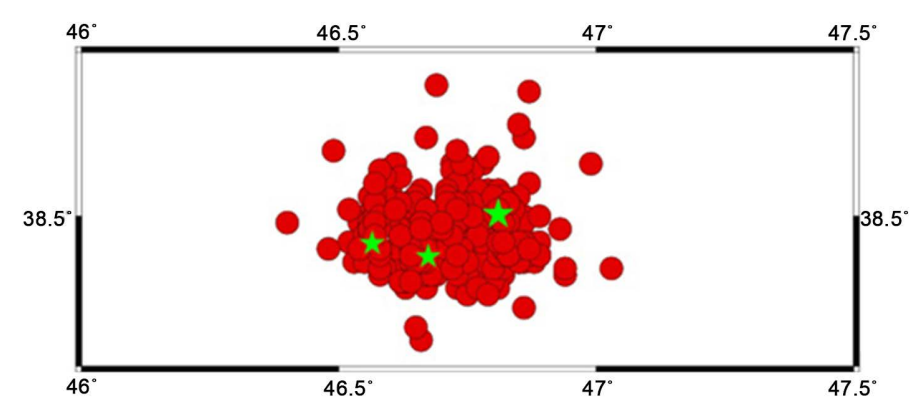

Figure 3. Epicenter of aftershocks $(M \geq 2.5)$ for the twin earthquakes of NW Iran on 11 August 2012 (star symbols show M > 5). 


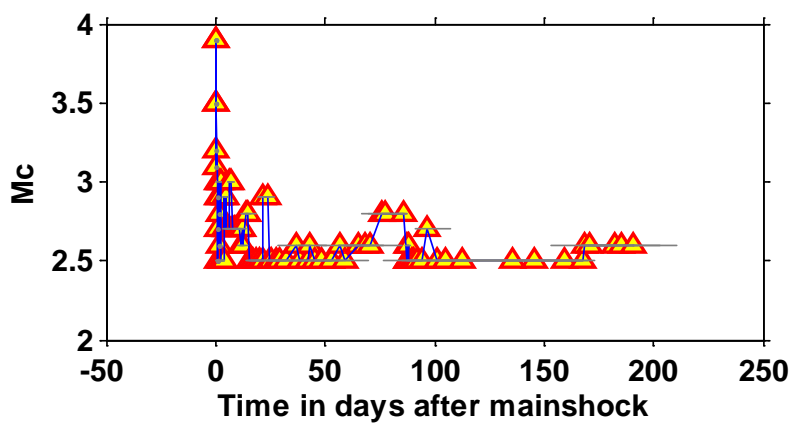

Figure 4. Magnitude of completeness as a function of time after the mainshocks (days) for duration of 2012/08/11 until 2013/03/30.

The constant $\mathrm{c}$ is influenced by incomplete detection of small aftershocks in the early stage of aftershocks [15]. P indicates how fast the aftershock rate decays with time and has a value close to 1.0 [6]. P-value varies between 0.6 and 1.8 [16], or changes from 0.5 to 1.8 [17]. P-value changes may be related to the tectonic condition of the region such as structural heterogeneity, stress and temperature or the crustal heat flow in the source volume [6] [15]. Therefore, it is not clear which factor is most significant in controlling the p-value [2]. In our catalog of aftershocks, the data show 494 events, most of which vary between 2.5 $\leq \mathrm{M} \leq 3.0$. According to the effects of the number of aftershocks, $\mathrm{p}$ and $\mathrm{c}$-values were experimented for the aftershocks based on the International Institute of Earthquake Engineering and Seismology (IIEES) catalog. In Figure 5, we showed the temporal decay rate of aftershocks for the Ahar-Varzeghan earthquakes. The $\mathrm{p}, \mathrm{c}$ and $\mathrm{K}$ parameters were obtained by the maximum likelihood method, and the occurrence rate was modeled by the modified Omori formula. Their values are: $\mathrm{p}=0.95+/-0.06, \mathrm{Mmin}=3.4, \mathrm{tmin}=0.006$ and $\mathrm{c}=0.037+/-$ 0.032 (Figure 5). Utsu et al. [6] believed that the p-value is independent of Mmin, but the c-value depends on the magnitude completeness of the data. On the other hand, [2] believed that the results did not change significantly. We tested Mmin between 2.5 (magnitude of completeness) until 4, we noticed that $\mathrm{p}$-values are not very dependent on the Mmin. They change very little, but $\mathrm{c}$-values depend on our selection of Mmin. We observed that c-value is dependent on the lower magnitude (Mmin), with c-value decreasing as Mmin increases. Our results are consistent with [6] and [17].

Some seismologists believe that P-value varies between 0.5 and 1.8 that our result ( $\mathrm{p}$-value $=0.95$ ) is in agreement with them. In addition, some researchers believe that the larger $c$-value ( $c>0.01$ days) reflects the more complicated characterization of the rupture process of the [18]. Others believe that the positive c-value is an under-estimated recording of small aftershocks instantly following a mainshock or the overlapping of seismic records in following of a strong earthquake. Moreover, another important reason is the lack of seismic stations close to the earthquake area [19]. Therefore, we introduce some calculations of 


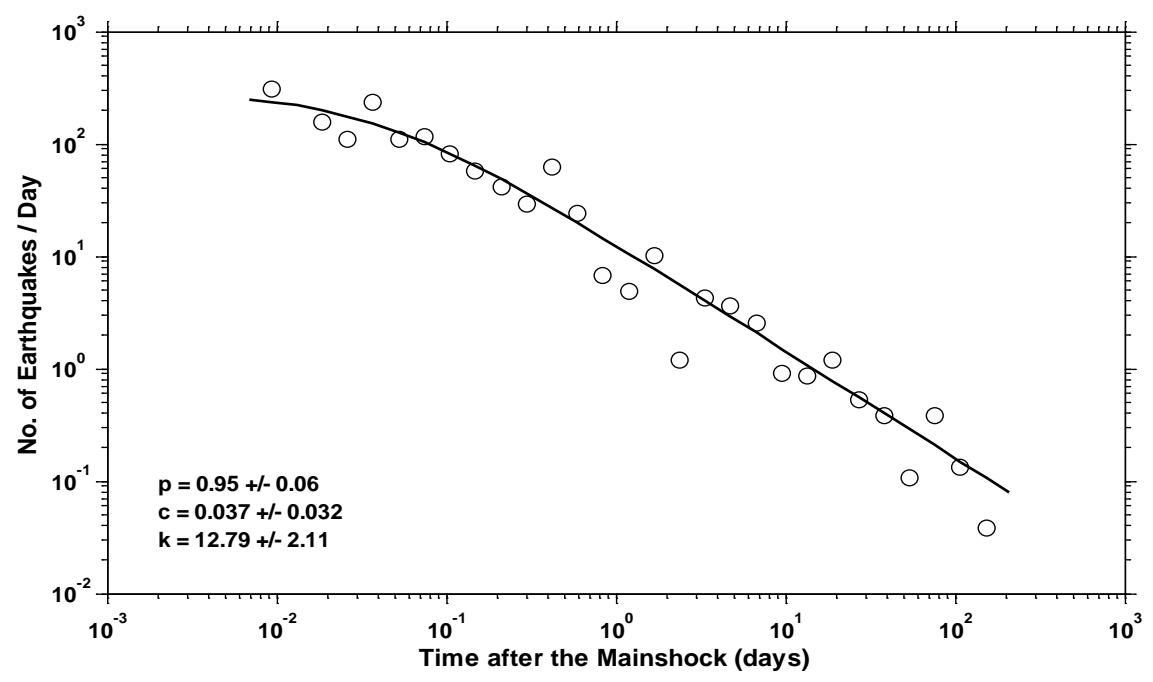

Figure 5. Temporal change in the number of Ahar-Varzeghan aftershocks per day (for the events $M \geq 3.4$ ). $p, c$ and $K$-values calculated by the modified Omori formula.

c-value for other regions in the world, for example: [20] found c $=0.02-0.5$ for 1969 Shikotan-Oki earthquake (M6.9; from [2] [6] obtained $c=0.03 \pm 0.03$ and $0.27 \pm 0.11$ for the Izmit and Duzce earthquakes, respectively.

Moreover, [21] studied on the aftershocks of the 2004 mid-Niigata earthquake $(\mathrm{Mw}=6.6)$, and their result for $\mathrm{c}$-value obtained $0.003 \pm 0.001$ days. In our study, c-value is about 0.03 that is consistent with the other studies compared with other regions.

Besides, we observed an aftershock in 7 November 2012, $M=5.6$, shown in Figure 6(a), in the left panel. We showed aftershocks following this aftershock $(\mathrm{M}=5.6)$ in the right panel of Figure $6(\mathrm{~b})$. We showed the temporal distribution of the aftershocks following the aftershock $(M=5.6)$ separately by the modified Omori law in Figure 7.

As a result, Aftershocks of the aftershock $(M=5.6)$ also decay according to the modified Omori law. We mentioned that the number of aftershocks cannot be counted completely in the beginning of aftershocks when smaller shocks are often obscured by larger ones due to the overlapping, then c-value obtain large value ( $c>0.01$ ). We believe that aftershocks are incomplete in the beginning of a sequence of aftershocks after the mainshocks (twin earthquakes in 11 August 2012), thus it is our reason for positive values of $c$. However, we obtained $c=0$ for aftershocks of the aftershock $(M=5.6)$, which is compatible with other comments such as, [6] and [22]. They believed that c-value might be equal to zero if all shocks should be counted. Besides, simple aftershock sequences following relatively small mainshocks, $c$-values usually assessed small about $\mathrm{c} \leq$ 0.01 days.

\section{Discussion on the Seismicity of North Tabriz Fault}

Some researchers in Taiwan proposed in their studies that the relatively low seismicity rate and the temporal decrease in the b-values before large 


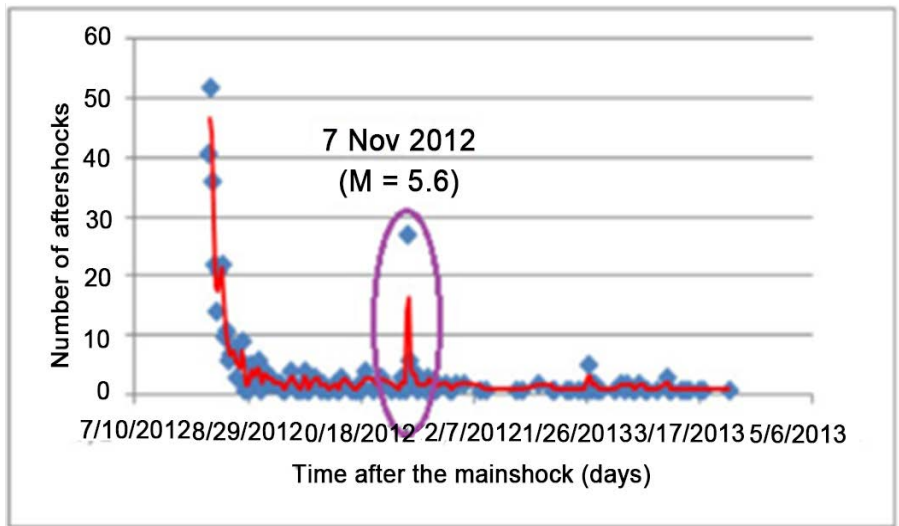

(a)

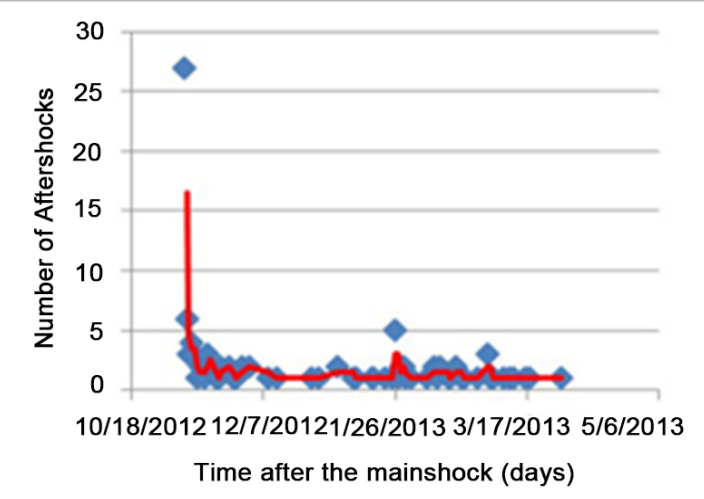

(b)

Figure 6. Number of aftershocks against Time (a) (left panel); Aftershocks of small mainshock $(\mathrm{M}=5.6)$ against Time (days), (b) (right panel).

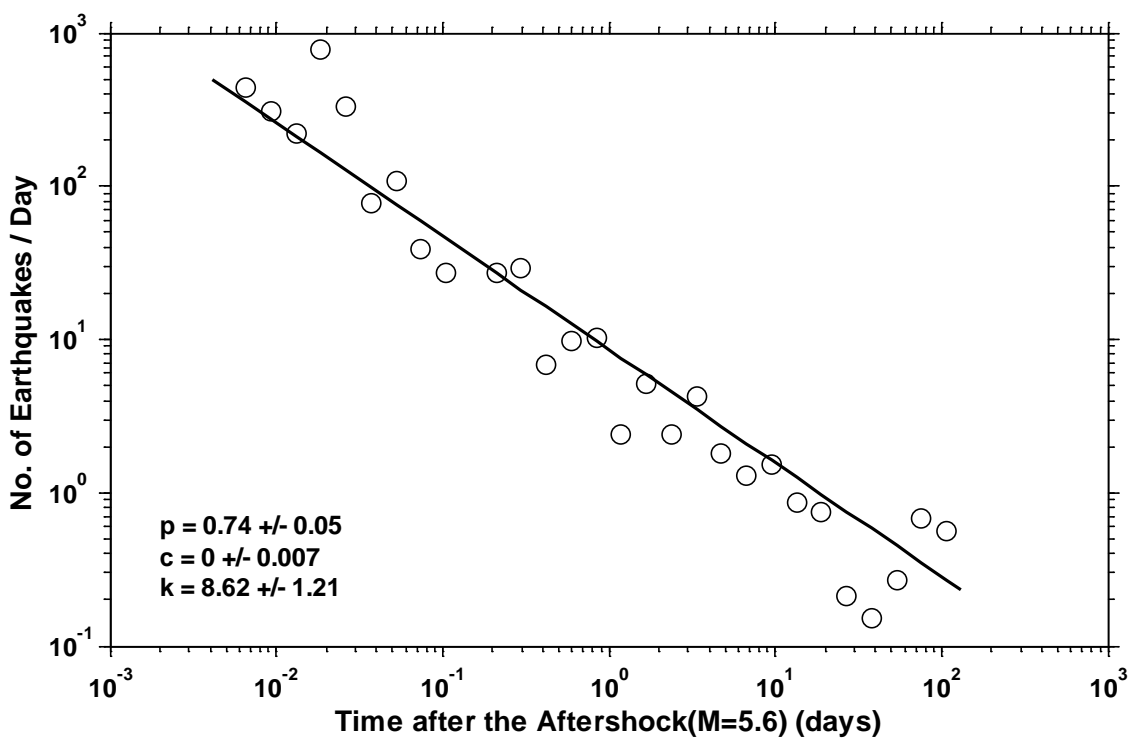

Figure 7. Temporal change in the number of aftershocks of the aftershock $(M=$ 5.6) per day (for the events $M \geq 2.5$ ). $\mathrm{p}$, c and $\mathrm{K}$-values calculated by the modified Omori formula.

earthquakes in Taiwan may be considered as a forecasting indicator associated with the quiescence in the seismicity with small magnitudes [23]. Then we use this idea for our data in Tabriz region especially for North Tabriz Fault region. Gutenberg and Richter, [3] introduced a description of the frequency of earthquakes:

$\log \mathrm{N} 10=\mathrm{a}-\mathrm{bM}$, where $\mathrm{N}$ is the cumulative number of earthquakes larger than magnitude $M$, and $a$ and $b$ are constants. The a-value is general level of seismicity for a region during the study period, and the higher a-value is, the higher the seismicity in the region [24]. The b-value is the slope of the Frequency-Magnitude Distribution that describes the relative size distribution of earthquakes. It depends on the stress regime and tectonic character of the region 
[24]-[29]. Kanamori, [30] stated that the lower b-value probably implies that the stress is high in the examined region. Decreasing b-value correlate with increasing stress levels before major events. Besides, Zhao and $\mathrm{Wu}$ [31] believe that $\mathrm{b}$-value can be related to stress heterogeneity or asperities. Asperities have higher potential for next strong earthquake [32]. The North Tabriz Fault (NTF) is an important fault in the east Azerbaijan province. We want to assess the effects of Ahar-Varzeghan earthquakes on NTF by determination of the temporal change of b-value before and after the twin mainshocks about $20 \mathrm{~km}$ around NTF.

For this part, Earthquake catalog provided by Iranian Seismological Center (IRSC) from 1996 to 2013 was selected because it includes magnitudes smaller than 2.5 too. Specifically the b-value of micro-earthquakes is the most important information for forecasting future events of M 5+ [33]. Our research for variations of b-value $20 \mathrm{~km}$ around NTF showed that it is not stationary. We obtained frequency-magnitude distribution of events in $20 \mathrm{~km}$ around NTF for before and after Ahar-Varzeghan twin earthquakes (Table $1 \&$ Figure 8(a) and Figure 8(b)). Based on our catalog for IRSC data, we observed a significant difference of b-value (approximately 0.1 ) for before and after twin earthquakes data. Therefore, we observed that the seismicity rate has changed in the region. b-value has changed to low before twin earthquakes and it increased after occurrence of them. Furthermore, we mapped spatial b-value distribution on NTF using maximum likelihood calculation for total of data in $20 \mathrm{~km}$ around NTF (Figure $8(\mathrm{c})$ ). The grid was taken as $0.05 \times 0.05$, with sampling radius of $20 \mathrm{~km}$.

Totally, we observed a result of the fact that b-value is low on NTF, and it is often less than one. Besides, temporal variations of $b$-value for the events in 20 $\mathrm{km}$ around NTF confirmed that b-value has increased after 2012 twin earthquakes in Ahar-Varzeghan region. Based on b-value around NTF (Figure 8(c)), It classified to three sections. In central-southern NTF, the minimum b-value was about 0.5 . In central NTF, the minimum b-value obtained about 0.6 and the maximum one was about 1.2. Moreover, b-value changes in central-northern was between 0.7 and 1.5 .

However, since the beginning of 2013, b-value is decreasing (Figure 8(d)), our data in the catalog cover the time period until May 2013. Sammonds et al., [34] believed that large earthquakes are often preceded by a medium-term (up to a couple of years) increase in b, followed by a decrease in the weeks-months before the earthquake that is compatible with our study on NTF. Moreover, other studies have confirmed that the b-value has decreased significantly prior to the occurrence of large earthquakes [35]. Our catalog showed that in the past 17 years no large event has occurred around NTF. Besides, studying the destructive historical earthquakes showed that the last strong earthquake with $M=7.7$ had occurred in 1780 caused by NTF. In the catalog, the earthquakes with $5.9 \leq \mathrm{M} \leq$ 7.7 were absent, for a time period of 101 years (up to 2013). Moreover, there is a 143-year seismic gap for the earthquake of $5.0 \leq \mathrm{M} \leq 7.7$ from the last moderate earthquake along NTF. The recent data shows that the seismicity rate is 
Table 1. b-value changes in $20 \mathrm{~km}$ around NTF for before and after Ahar-Varzeghan twin earthquakes.

\begin{tabular}{ccc}
\hline Region & $b$-value & a-value \\
\hline $20 \mathrm{~km}$ around NTF for before the Ahar-Varzaghan earthquakes & 0.780 & 4.19 \\
$20 \mathrm{~km}$ around NTF for after the Ahar-Varzaghan earthquakes & 0.888 & 3.83 \\
\hline
\end{tabular}

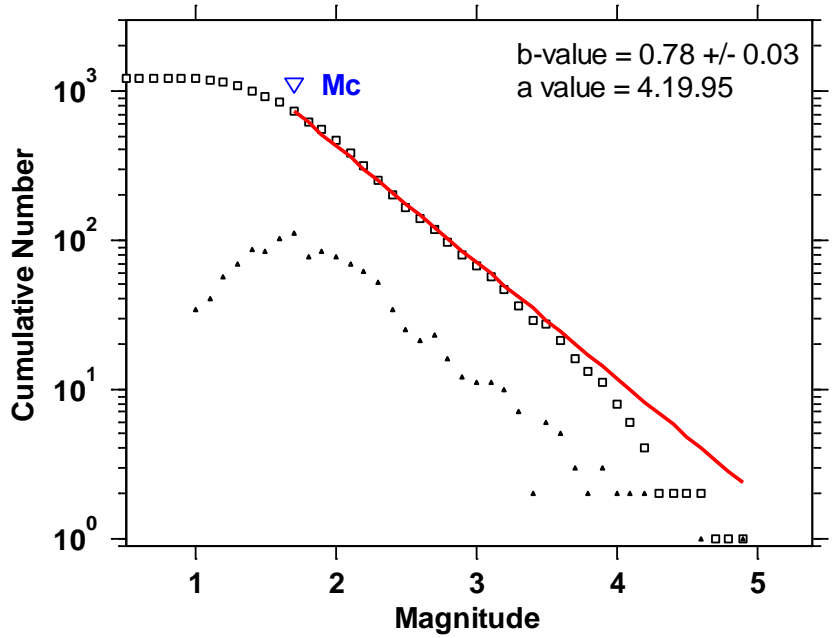

(a)

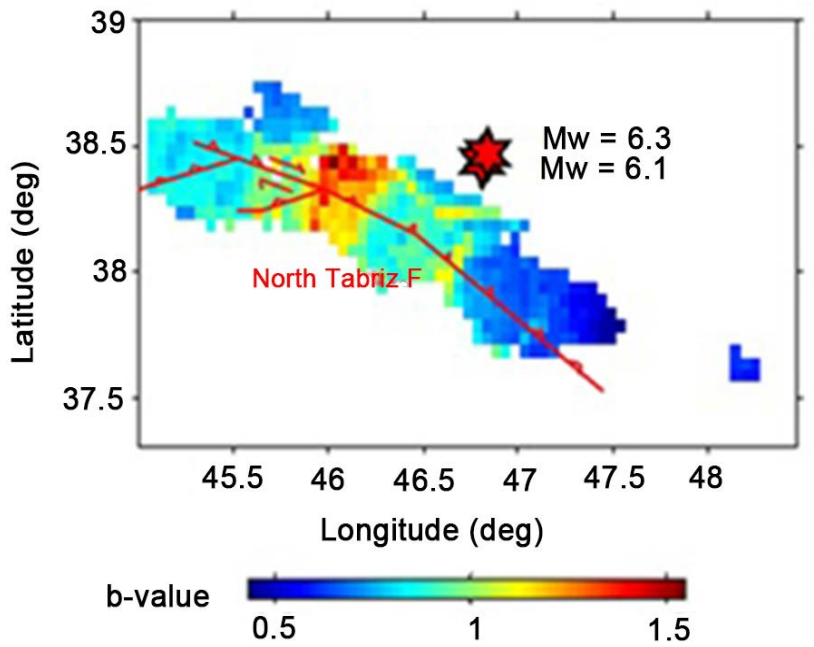

(c)

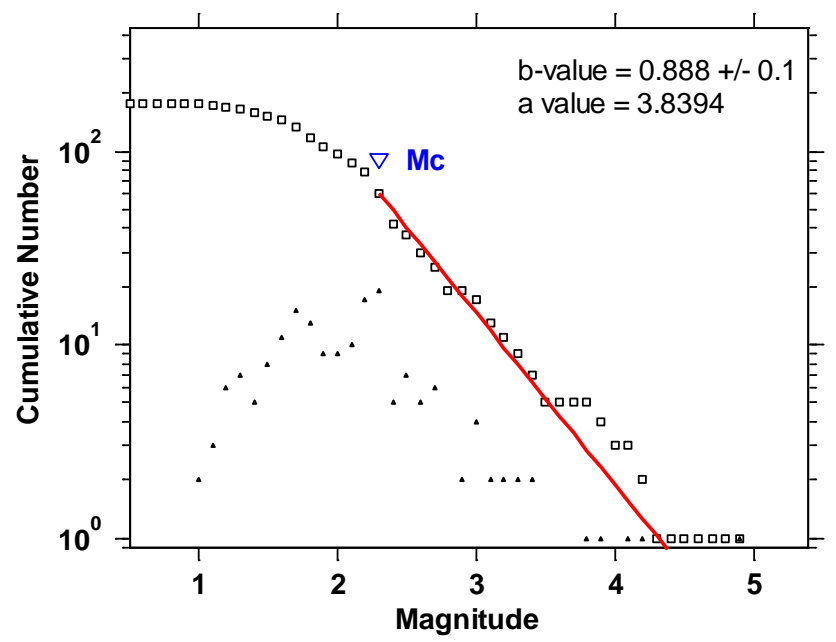

(b)

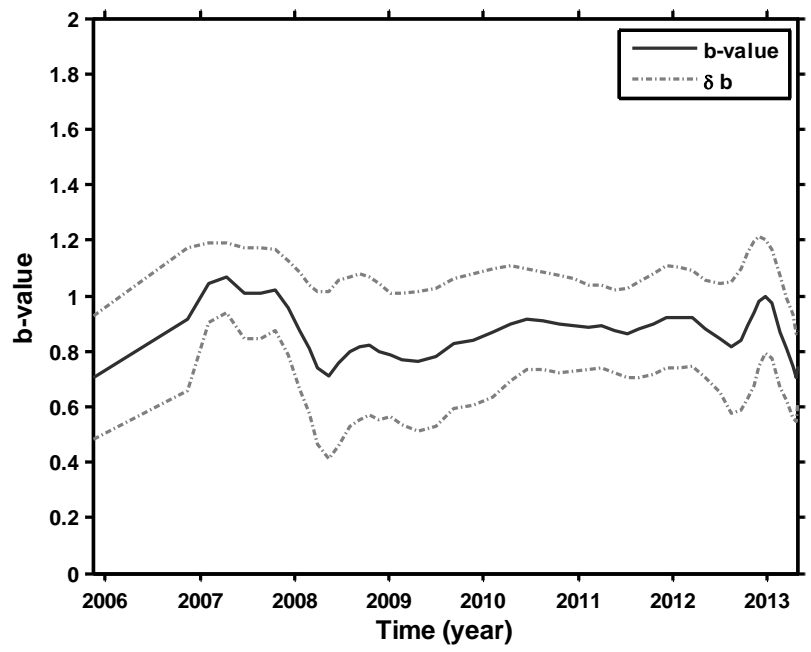

(d)

Figure 8. Frequency-magnitude distribution for before (Left-a) and after (right-b) Ahar-Varzeghan twin earthquakes calculated with maximum likelihood method (Data for $20 \mathrm{~km}$ around NTF). (c) Spatial distribution of b-value in $20 \mathrm{~km}$ around NTF computed with the IRSC catalog $(1996-2103)$, centered at grid $(0.05 \times 0.05)$ nodes. Stars mark the Ahar-Varzeghan Twin earthquakes. (d) Temporal changes in b value versus time for $20 \mathrm{~km}$ around NTF; Dashed lines indicate the standard deviation.

currently changing after 2012 twin earthquakes in Varzeghan, on NTF specially based on b-value changes. Therefore, based on 1) studies of b-value 2) the last historical earthquakes and 3) the lack of a strong earthquake for instrumental data on NTF (Figure 9), we conclude a warning for a possible strong earthquake along NTF for coming couple of years. 

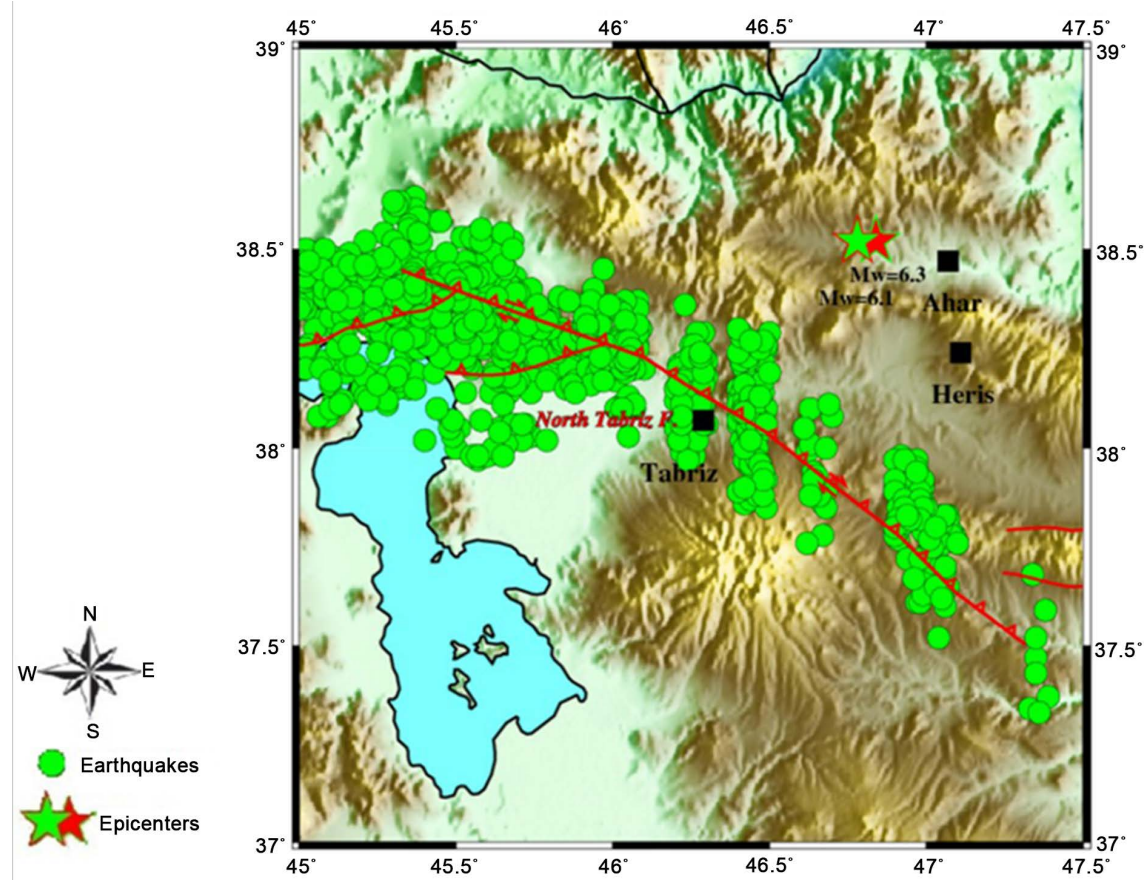

Figure 9. Epicenter map of earthquakes approximately $20 \mathrm{~km}$ around North Tabriz Fault NTF.

According to these reasons and our observations about seismic gap, this event may occur more probably in the central or central-southern portion of NTF. Having more complete seismicity data as for regional and local scales along NTF, we could forecast such major $(M>7.0)$ event more precisely. Results from our study suggest that the monitoring of seismic rate variation is an important task. Besides, the changes in b-value and seismic rate during 1996-2013 along NTF may have been a warning sign that creeping sections of fault often b-values is high [36] [37] and [38], the part that is shown with arrows in Figure 8(c). Therefore, the rate of seismicity and b-value monitoring in both time and space are necessary for more accurate further studies.

\section{Conclusion}

The statistical properties of aftershocks of Ahar-Varzeghan Twin Earthquakes on 11 August 2012 are investigated in Tabriz region. We achieved that aftershocks for a strong motion as well as aftershocks of aftershocks decay according to the modified Omori law. In our study, p-value is about 0.95 , which compared with other researches ( $\mathrm{P}$-value range is between $0.5-1.8$ ), our result is consistent with this range. The b-value estimated $0.888 \pm 0.1$ for the aftershocks of Ahar twin earthquakes. Based on the result of $c$-value $=0.03$ ( $c>0.01$ ), it may be caused by the incompleteness at the starting sequence of aftershocks, not related to the complex aspect of the rupture process of the mainshock for Ahar Twin earthquakes. Based on our research on the instrumental and historical data and also b-value studies, we estimate a warning in the central or central-southern 
portion of the North Tabriz Fault for the coming couple of years.

\section{Data and Resources}

The waveform data and catalog for earthquakes from the Broadband Iranian Network (BIN) of the International Institute of Earthquake Engineering and Seismology (IIEES) were searched using http://www.iiees.ac.ir/ (last accessed March 2013). Besides, we used catalog for earthquakes from the Institute of Geophysics, University of Tehran (IGUT), by request from the Iranian Seismological Center (IRSC), http://irsc.ut.ac.ir/ (last accessed in May 2013). We used the software ZMAP [39] in our computations.

\section{References}

[1] Vasheghani-Farahani, J. and Zaré, M. (2014) Seismological Aspects of the Varzeghan Twin Earthquakes on 11 August 2012 (Mw 6.3 and Mw 6.1), in East Azerbaijan Province, NW Iran. Episodes, 37, 96-110.

[2] Bayrak, Y. and Ozturk, S. (2004) Spatial and Temporal Variations of the Aftershock Sequencesof the 1999 Izmit and Duzce Earthquakes. Earth, Planets and Space, 56, 933-944. https://doi.org/10.1186/BF03351791

[3] Gutenberg, B. and Richter, C. (1944) Frequency of Earthquakes in California. Bulletin of the Seismological Society of America, 34, 185-188.

[4] Lay, T. and Wallace, T.C. (1995) Modern Global Seismology. Academic Press, San Diego, 521.

[5] Scholz, C.H. (2002) The Mechanics of Earthquakes and Faulting. Cambridge University Press, New York. https://doi.org/10.1017/CBO9780511818516

[6] Utsu, T., Ogata, Y. and Matsu'ura, R.S. (1995) The Centenary of the Omori Formula for Decay Law of Aftershock Activity. Journal of Physics of the Earth, 43, 1-33. https://doi.org/10.4294/jpe1952.43.1

[7] Hessami , K., Pantosti, D., Tabassi, H., Shabanian, E., Abbassi, M.R., Feghhi, K. and Solaymani, S. (2003) Paleoearthquakes and Slip Rates of the North Tabriz Fault, NW Iran: Preliminary Results. Annals of Geophysics, 46, 903-915.

[8] Berberian, M. and Arshadi, S. (1976) On the Evidence of the Youngest Activity of the North Tabriz Fault and the Seismicity of Tabriz City. Geological Survey of Iran, 39, 397-418.

[9] Berberian, M. (1997) Seismic Sources of the Transcaucasian Historical Earthquakes. In: Giardini, D. and Balassanian, S., Eds., Historical and Prehistorical Earthquakes in the Caucasus, NATO ASI Series 2, Environment-28, Kluwer Academic Press, The Netherlands, 233-311. https://doi.org/10.1007/978-94-011-5464-2_13

[10] Kisslinger, C. (1996) Aftershocks and Fault Zone Properties. Advances in Geophysics, 38, 1-36. https://doi.org/10.1016/S0065-2687(08)60019-9

[11] Shcherbakov, R., Turcotte, D.L. and Rundle, J.B. (2004) A Generalized Omori's Law for Earthquake Aftershock Decay. Geophysical Research Letters, 31, L11613. https://doi.org/10.1029/2004GL019808

[12] Rydelek, P.A. and Sacks, I.S. (1989) Testing the Completeness of Earthquake Catalogs and the Hypothesis of Self-Similarity. Nature, 337, 251-253. https://doi.org/10.1038/337251a0

[13] Woessner, J. and Wiemer, S. (2005) Assessing the Quality of Earthquake Catalogs: 
Estimating the Magnitude of Completeness and Its Uncertainty. Bulletin of the Seismological Society of America, 95, 684-698.

[14] Wiemer, S. and Katsumata, K. (1999) Spatial Variability of Seismicity Parameters in Aftershock Zones. Journal of Geophysical Research, 104, 13135-13151. https://doi.org/10.1029/1999JB900032

[15] Kisslinger, C. and Jones, L.M. (1991) Properties of Aftershock Sequences in Southern California. Journal of Geophysical Research, 96, 11947-11958. https://doi.org/10.1029/91JB01200

[16] Olsson, R. (1999) An Estimation of the Maximum $b$-Value in the Gutenberg-Richter relation. Geodynamics, 27, 547-552. https://doi.org/10.1016/S0264-3707(98)00022-2

[17] Shcherbakov, R., Nguyena, M. and Quigley, M. (2012) Statistical Analysis of the $2010 M_{\mathrm{w}} 7.1$ Darfield Earthquake Aftershock Sequence. New Zealand Journal of Geology and Geophysics, 55, 305-311. https://doi.org/10.1080/00288306.2012.676556

[18] Yamakawa, N. (1968) Foreshocks, Aftershocks, and Earthquake Swarms (IV) -Frequency Decrease of Aftershocks in Its Initial and Later Stages. Papers in $\mathrm{Me}$ teorology and Geophysics, 19, 109-119.

[19] Kagan, Y.Y. and Houston, H. (2005) Relation between Mainshock Rupture Process and Omori's Law for Aftershock Moment Release Rate. Geophysical Journal International, 163, 1039-1048. https://doi.org/10.1111/j.1365-246X.2005.02772.x

[20] Hirata, T. (1969) Aftershock Sequence of the Earthquake Off Shikotan Island on January 29, 1968. Geophysical Bulletin of Hokkaido University, 21, 33-43. (In Japanese)

[21] Enescu, B., Mori, J. and Miyazawa, M. (2007) Quantifying Early Aftershock Activity of the 2004 Mid-Niigata Prefecture Earthquake $\left(M_{\mathrm{w}} 6.6\right)$. Journal of Geophysical Research, 112, 1-10. https://doi.org/10.1029/2006JB004629

[22] Utsu, T. (1971) Aftershocks and Earthquake Statistics (III) - Analyses of the Distribution of Earthquakes in Magnitude, Time, and Space with Special Consideration to Clustering Characteristics of Earthquake Occurrence (1). Journal of the Faculty of Science, Hokkaido University, Series 7, Geophysics, 3, 379-441.

[23] Chan, C., Wu, H., Tseng, Y.M., Lin, T.L. and Chen, C.C. (2012) Spatial and Temporal Evolution of $b$-Values before Large Earthquakes in Taiwan. Tectonophysics, 532-535, 215-222. https://doi.org/10.1016/j.tecto.2012.02.004

[24] Nuannin, P. (2006) The Potential of $b$-Value Variations as Earthquake Precursors for Small and Large Events. Ph.D. Thesis, Acta Universitatis Upsaliensis, Uppsala, 1651-6214.

[25] Allen, C., Amand, P., Richter, C. and Nordquist, J. (1965) Relation between Seismicity and Geological Structure in the Southern California Region. Bulletin of the Seismological Society of America, 55, 753-797.

[26] Mogi, K. (1967) Regional Variation in Magnitude-Frequency Relation of Earthquake. Bulletin of the Seismological Society of America, 45, 313-325.

[27] Scholz, C.H. (1968) The Frequency-Magnitude Relation of Micro-Fracturing in Rock and Its Relation to Earthquakes. Bulletin of Seismological Society of America, 58, 399-415.

[28] Hatzidimitriou, P.M., Papadimitriou, E.E., Mountrakis, D.M. and Papazachos, B.C. (1985) The Seismic Parameter $b$ of the Frequency-Magnitude Relation and Its Association with the Geological Zones in the Area of Greece. Tectonophysics, 120, 141-151. https://doi.org/10.1016/0040-1951(85)90092-7

[29] Tsapanos, T. (1990) b-Value of Two Tectonic Parts in the Circum-Pacific Belt. Pure 
and Applied Geophysics, 143, 229-242. https://doi.org/10.1007/BF00876999

[30] Kanamori, H. (1981) The Nature of Seismic Patterns before Large Earthquakes. In: Simpson, D.W. and Richards, P.G., Eds., Earthquake Prediction: An International Review (Maurice Ewing Series), Volume 4, AGU, Washington D.C., 1-19.

[31] Zhao, Y.Z. and Wu, Z.L. (2008) Mapping the $b$-Values along the Longmenshan Fault Zone before and after the 12 May 2008, Wenchuan, China, $M_{\mathrm{S}} 8.0$ Earthquake. Natural Hazards and Earth System Sciences, 8, 1375-1385. https://doi.org/10.5194/nhess-8-1375-2008

[32] Yi, G.-X., Wen, X.-Z. and Su, Y.-J. (2008) Study on the Potential Strong-Earthquake Risk for the Eastern Boundary of the Sichuan-Yunnan Active Faulted-Block, China. Chinese Journal of Geophysics, 51, 1151-1158. https://doi.org/10.1002/cjg2.1311

[33] Wiemer, S. and Schorlemmer, D. (2007) ALM: An Asperity-Based Likelihood Model for California. Seismological Research Letters, 78, 134-140. https://doi.org/10.1785/gssrl.78.1.134

[34] Sammonds, P.R., Meredith, P.G. and Main, I.G. (1992) Role of Pore Fluid in the Generation of Seismic Precursors to Shear Fracture. Nature, 359, 228-230. https://doi.org/10.1038/359228a0

[35] Monterroso, D. (2003) Statistical Seismology Studies in Central America: $b$-Value, Seismic Hazard and Seismic Quiescence. Ph.D. Thesis, Acta Universitatis Upsaliensis, Uppsala.

[36] Amelung, F. and King, G. (1997) Earthquake Scaling Laws for Creeping and Non-Creeping Faults. Geophysical Research Letters, 24, 507-510. https://doi.org/10.1029/97GL00287

[37] Wiemer, S. and Wyss, M. (1997) Mapping the Frequency-Magnitude Distribution in Asperities: An Improved Technique to Calculate Recurrence Times? Journal of Geophysical Research, 102, 15115-15128. https://doi.org/10.1029/97JB00726

[38] Wyss, M. (2001) Locked and Creeping Patches along the Hayward fault, California. Geophysical Research Letters, 28, 3537-3540. https://doi.org/10.1029/2001GL013499

[39] Wiemer, S. (2001) A Software Package to Analyze Seismicity: ZMAP. Seismological Research Letters, 72, 373-382. https://doi.org/10.1785/gssrl.72.3.373 